\title{
Enhanced removal of phenolic endocrine disrupting chemicals from coastal waters by intertidal macroalgae
}

\author{
Cui Zhang ${ }^{\mathrm{a}, \mathrm{b}}$, Jian $\mathrm{Lu}^{\mathrm{a}, \mathrm{b}, \mathrm{c}, *}$, Jun Wu ${ }^{\mathrm{d}}$ \\ ${ }^{\text {a }}$ CAS Key Laboratory of Coastal Environmental Processes and Ecological Remediation, Yantai Institute of Coastal Zone Research (YIC), Chinese Academy of Sciences \\ (CAS), Yantai, Shandong 264003, PR China \\ b Shandong Key Laboratory of Coastal Environmental Processes, YICCAS, Yantai, Shandong 264003, PR China \\ ${ }^{\mathrm{c}}$ Center for Ocean Mega-Science, Chinese Academy of Sciences, 7 Nanhai Road, Qingdao 266071, PR China \\ ${ }^{\mathrm{d}}$ Yantai Research Institute and Graduate School, Harbin Engineering University, Yantai, Shandong 265501, PR China
}

\section{A R T I C L E I N F O}

Editor: Dr. D. Aga

\section{Keywords:}

Natural attenuation

Bisphenol A

Nonylphenol

Seaweed

Ulva pertusa

\begin{abstract}
A B S T R A C T
The phytoremediation of phenolic endocrine disrupting compounds (EDCs) in coastal waters by intertidal macroalgae was firstly investigated. The results showed that intertidal macroalgae could remove bisphenol A (BPA) and nonylphenol (NP) at environmental relevant concentration, and Ulva pertusa was the most efficient one. In most cases, the order of EDCs removal efficiency could be expressed as: green algae $>$ brown algae $>$ red algae. The in-situ monitoring using a charge-coupled device imaging system confirmed the accumulation of EDCs in the intertidal macroalgae. The removal mechanisms included the initial rapid biosorption process, followed by the slow accumulation and biodegradation. The removal efficiency of BPA and NP was slightly dependent on temperature and nutrient concentration. A linear relationship was observed between the initial concentration and the average removal rate $\left(R^{2}>0.99\right)$. The BPA and NP at the environmental relevant concentration $(100 \mu \mathrm{g}$ $\mathrm{L}^{-1}$ ) could be removed efficiently using Ulva pertusa even after three cycles in pilot-scale experiments. The high removal efficiency of NP and BPA was also confirmed by the field investigation from the intertidal zone with abundant Ulva pertusa. These findings demonstrated that intertidal macroalgae could play essential role for the phytoremediation of phenolic EDCs in coastal waters.
\end{abstract}

\section{Introduction}

Macroalgae are highly abundant in the littoral zone. The common intertidal macroalgae mainly include green alga (e.g., Ulva pertusa, Ulva prolifera, and Codium fragile), red alga (e.g., Gracilaria asiatica, Gymnogongrus flabelliformis, and Gracilaria lemaneiformis), and brown alga (e.g., Laminaria japonica, Sargassum hornori, and Scytosiphon lomentaria) (El Gamal, 2010; Fabre et al., 2020). The ecological service functions of macroalgae could embrace water aeration, water purification, suppression of harmful microorganisms, and shelter for aquatic animals (Bazterrica et al., 2021; Naiel et al., 2020). Ulva pertusa (U. pertusa) is a typical green macroalgae and distributed widely in the intertidal zone (Sun et al., 2018). It has become a predominant species for the biofilter of mariculture system due to its high biomass and bioactive compounds production, extensive environmental tolerance, and high biofiltration efficiency (Brito et al., 2014). Some studies have demonstrated that $U$. pertusa could absorb and metabolize inorganic nitrogen and phosphorus nutrients efficiently from industrial and aquaculture wastewater (Amosu et al., 2016; Liu et al., 2010). However, little research has been done on emerging contaminants, especially endocrine disrupting chemicals (EDCs). Our previous investigations have demonstrated that the harmful green tidal algae (Ulva prolifera) had great potential on the removal of organic contaminants at the environmental relevant concentration (Zhang et al., 2017, 2019a, 2019b). Therefore, it is hypothesized that the prevalent intertidal macroalgae may possess a high removal potential for emerging contaminants.

Phenolic EDCs such as nonylphenol (NP) and bisphenol A (BPA) have attracted public attention in the last few decades due to their adverse impact on the endocrine system and even the reproductive system of organisms (Lu et al., 2015). Both BPA and NP were detected with high frequency in coastal waters such as ports and bathing beaches according to the previous study to indicate a significant potential exposure pathway for humans (Lu et al., 2020a, 2020b). Significantly, large populations, active industrialization, and an increase in consumption of

\footnotetext{
* Corresponding author at: Shandong Key Laboratory of Coastal Environmental Processes, YICCAS, Yantai, Shandong 264003, PR China.

E-mail address: jlu@yic.ac.cn (J. Lu).
} 
plastic products have added the potential threat of emerging pollutants, especially phenolic EDCs to coastal environments (Lu et al., 2019, 2020b, 2020c, 2021). Several studies have demonstrated that microalgae could accumulate EDCs from freshwater aquatic environments (Abargues et al., 2018; Bai and Acharya, 2019; Cheng et al., 2020; Wang et al., 2017). The removal efficiencies of EDCs by these algae were proved highly algal species-specific and affected by various factors, such as $\mathrm{pH}$, temperature, and light. The biodegradation efficiency of NP was positively related to temperature and light intensity. Wang et al. (2017) reported that the removal of BPA by Desmodesmus sp. WR1 (green microalgae) depended on initial BPA concentration. However, rare information is available on the role of macroalgae, especially intertidal macroalgae, in the fate of phenolic EDCs in coastal water.

Typical intertidal macroalgae were selected in this study to investigate their removal behaviors on the target phenolic EDCs such as BPA and NP. Simultaneously, the effects of photoperiod, nutrient concentration, salinity, temperature, and initial concentration of contaminants on the removal of EDCs were evaluated. The aim was to obtain initial information on the removal potential and mechanisms of EDCs from coastal waters using intertidal macroalgae, which was beneficial for understanding the natural attenuation of phenolic EDCs and related ecological remediation in coastal zones.

\section{Material and methods}

\subsection{Chemicals and materials}

NP was purchased from Aladdin Industrial Co. (California, USA) with a purity of $98 \%$, while BPA (purity $>99 \%$ ) was obtained from Macklin Biochemical Co., Ltd (Shanghai, China). Phenanthrene- $d_{10}$ (phe- $d_{10}$, GCMS analysis) was supplied by Dr. Ehrenstorfer GmbH (Augsburg, Germany). N, O-bis(trimethylsilyl)trifluoroacetamide (BSTFA) and trimethylchlorosilane (TMCS) with purity more than 98\% were both purchased from Alfa Aesar Inc. (Ward Hill, MA). All solvents applied, such as methanol, acetonitrile, and dichloromethane, were HPLC grade. Sodium nitrate, anhydrous sodium sulfate, sodium hydrogen phosphate, sodium hydroxide, and hydrochloric acid were analytical reagents. The stock solutions of BPA and NP $\left(1 \mathrm{~g} \mathrm{~L}^{-1}\right)$ were prepared by using methanol as solvent. The working solutions of NP or BPA were obtained individually by diluting stock solutions $\left(1 \mathrm{~g} \mathrm{~L}^{-1}\right)$ with sterile seawater to target concentration.

\subsection{Intertidal macroalgae and seawater for experiments}

Fresh Ulva pertusa (U. pertusa), Ulva prolifera (U. prolifera), Sargassum horueri (S. horueri), Gymnogongrus flabelliformis (G. flabelliformis), Gracilaria lemaneiformis (G. lemaneiformis) and Codium fragile (C. fragile) were collected from the coastal water of Yantai City (China) on September 12, 2019. In the laboratory, the algae were cleaned with sterile seawater and incubated at $10{ }^{\circ} \mathrm{C}$ in a temperature-controlled incubator (GXZ-380B-LED, Ningbo Jiangnan Inc., China) with an irradiance of $100 \mu \mathrm{mol}$ photons $\mathrm{m}^{-2} \mathrm{~s}^{-1}$. The light/dark cycle was conducted as $12 / 12$. The incubated medium was renewed entirely every week. Before the incubation experiments, the algae were transferred to an experimental incubator with a target temperature under the same incubation condition for $48 \mathrm{~h}$. Natural seawater was obtained from the coast of Yantai city and filtered by glass fiber papers $(0.22 \mu \mathrm{m}$ pore size $)$ before used.

\subsection{Lab-scale experiments}

The removal of BPA and NP by six common intertidal macroalgae (U. pertusa, U. prolifera, S. horueri, G. flabelliformis, G. lemaneiformis and C. fragile) was evaluated in a $500 \mathrm{~mL}$ beaker containing $400 \mathrm{~mL}$ sterilized seawater with target phenolic EDCs $\left(100 \mu \mathrm{g} \mathrm{L}^{-1}\right)$ and algae $(4 \mathrm{~g}$ $\mathrm{L}^{-1}$ ). All beakers were shaken twice at a fixed time every day to enhance the mass transfer process. Heat-killed $U$. pertusa treatment by autoclaving live algae at $121{ }^{\circ} \mathrm{C}$ for $20 \mathrm{~min}$ before the experiment was prepared to further explore BPA and NP removal potential by $U$. pertusa. The abiotic controls with only BPA or NP were conducted to monitor the abiotic loss of BPA or NP. Biotic controls were also performed by adding live $U$. pertusa and BPA or NP to natural seawater without sterilization to observe the effect of microorganisms. Aqueous samples were collected at given time intervals and analyzed by ultra-high-performance liquid chromatography (UHPLC). The algal samples after reaction were collected and analyzed by gas chromatography-mass spectrometry (GCMS).

To evaluate the influence of photoperiod, the light/dark cycle was set as $0 / 24,12 / 12$, and $24 / 0$ by a temperature-controlled incubator. To achieve the effect of salinity, different salinity $\left(16,24\right.$, and $\left.32 \mathrm{~g} \mathrm{~L}^{-1}\right)$ were obtained by diluting the seawater with a certain amount of ultrapure water. Various incubation temperature treatments $\left(10^{\circ} \mathrm{C}, 20^{\circ} \mathrm{C}\right.$, and $30^{\circ} \mathrm{C}$ ) were conducted to obtain the influence of temperature. Low $\left(0 \mathrm{mg} \mathrm{L}^{-1}\left(\mathrm{NO}_{-3}-\mathrm{N}\right) / 0 \mathrm{mg} \mathrm{L}^{-1}\left(\mathrm{PO}_{3-4}-\mathrm{P}\right)\right)$, middle $\left(1.0 \mathrm{mg} \mathrm{L}^{-1}\left(\mathrm{NO}_{-3}-\mathrm{N}\right) /\right.$ $0.25 \mathrm{mg} \mathrm{L}^{-1}\left(\mathrm{PO}_{3-4}-\mathrm{P}\right)$ ), and high $\left(3.0 \mathrm{mg} \mathrm{L}^{-1}\left(\mathrm{NO}_{3}-\mathrm{N}\right) / 0.75 \mathrm{mg} \mathrm{L}^{-1}\right.$ $\left(\mathrm{PO}_{3-4} \mathrm{P}\right)$ ) nutrient concentrations were set to explore the influence of nutrient concentrations on phenolic EDCs removal by live $U$. pertusa. Besides, various initial concentrations of BPA or NP were obtained by diluting the stock solution with sterile seawater to 50,100, 200,500, and $1000 \mu \mathrm{g} \mathrm{L}^{-1}$ to evaluate the effect of the initial concentration of the phenolic EDCs on removal efficiency.

\subsection{Pilot-scale experiments}

To predict the behavior of two targets phenolic EDCs in real seawater, the pilot-scale experiments were conducted in recycle mode. The experiments were investigated in $70 \mathrm{~L}$ glass tanks containing $50 \mathrm{~L}$ raw water, which was the wastewater from the mariculture system. The pilot-scale experiments involved two parallel treatments: control treatment without $U$. pertusa addition and $U$. pertusa treatment. The algal content was $4 \mathrm{~g} \mathrm{~L}^{-1}$. The BPA and NP were added simultaneously into the incubation tank, and the initial concentration was adjusted to 100 $\mu \mathrm{g} \mathrm{L}^{-1}$. The cycle number was set as 3 . In each cycle, the concentrations of target contaminants during the pilot-testing period were measured at time-dependent intervals. At the end of each cycle, water quality parameters, such as $\mathrm{pH}$, dissolved oxygen (DO), and nutrients, were also monitored. Meanwhile, the target contaminants were supplemented after both BPA and NP exhausted in the medium.

\subsection{Field investigation}

The field investigation was performed and seawater samples (U1, U2, and U3) were collected in the coastal area of Yantai city (China), where the $U$. pertusa was abundant. Simultaneously, the control water samples (C1, C2, and C3) were also collected from the adjacent area without $U$. pertusa. The two sampling locations were chosen for evaluating the phytoremediation of the coastal water polluted with NP and BPA in the presence of intertidal macroalgae. Surface water samples, $0.3 \mathrm{~m}$ below the air-water interface, were collected with $1 \mathrm{~L}$ pre-cleaned amber glass sample bottles. All of the samples were quickly transported to the laboratory for NP and BPA analysis.

\subsection{Analytical methods}

2.6.1. Determination of BPA and NP concentrations in aqueous solutions

In laboratory and pilot-scale experiments, the aqueous sample was initially centrifuged at $12,000 \mathrm{rpm}$ for 6 min to obtain supernatant and then analyzed by UHPLC equipped with a fluorescence detector (Waters, Milford, USA). These contaminants were separated by a $\mathrm{C}_{18}$ reversephase column $(2.1 \times 50 \mathrm{~mm}, 1.7 \mu \mathrm{m}$, Waters, USA). The mobile phases for BPA and NP were $\mathrm{H}_{2} \mathrm{O} /$ methanol $(40 / 60, v / v \%)$ and $\mathrm{H}_{2} \mathrm{O}$ / acetonitrile $(30 / 70, \mathrm{v} / \mathrm{v} \%)$, respectively. The flow rates were both set at 
$0.3 \mathrm{~mL} \mathrm{~min}^{-1}$. The injection volume was $10 \mu \mathrm{L}$, and fluorescence of the BPA and NP compounds was monitored at $305 / 225 \mathrm{~nm}\left(\lambda_{\mathrm{ex}} / \lambda_{\mathrm{em}}\right)$ and $277 / 300 \mathrm{~nm}\left(\lambda_{\mathrm{ex}} / \lambda_{\mathrm{em}}\right)$, respectively. BPA and NP were extracted through liquid-liquid extraction (LLE) and then analyzed by GC-MS to monitor the BPA and NP concentration in the coastal water samples collected for field investigation. Detailed information about the analytical procedures has been fully described in our recent study (Lu et al., 2020a).

\subsubsection{Determination of BPA and NP concentrations in algae samples}

To monitor the BPA and NP concentration in algae samples, the BPA and NP were extracted by accelerated solvent extraction (ASE) apparatus and then analyzed by GC-MS. The extraction methods for BPA and NP in algae samples referred to the previously developed methods (Zhang et al., 2019b). The extracted liquid was concentrated smoothly to dryness by nitrogen stream, then exchanged into $100 \mu \mathrm{L}$ n-hexane and made derivatization at $70{ }^{\circ} \mathrm{C}$ with $50 \mu \mathrm{L}$ BSTFA (containing $1 \%$ TMCS) for $2 \mathrm{~h}$ before GC-MS analysis.

The concentration of BPA and NP in algae extraction samples were analyzed by an Agilent 7820 A GC system (Palo Alto, CA, USA) coupled to an M7 single quadrupole MS system (Persee Co., Beijing, China), equipping with a $30 \mathrm{~m}$ DB-5MS column $(0.25 \mathrm{~mm}$ I.D, Agilent $\mathrm{J} \& \mathrm{~W}$ Scientific, Palo Alto, CA, USA). The extracted sample with a volume of 1 $\mu \mathrm{L}$ was injected in splitless mode with helium as a carrier gas. The temperature program for column oven was set at $100^{\circ} \mathrm{C}$ for $2 \mathrm{~min}$, then increased to $280{ }^{\circ} \mathrm{C}$ at a $20^{\circ} \mathrm{C} \mathrm{min}{ }^{-1}$ rate and kept for $1 \mathrm{~min}$. The total runtime was $12.00 \mathrm{~min}$, including a solvent delay time of $8 \mathrm{~min}$. The temperatures of the injector, transfer line, and ion source were held at $280{ }^{\circ} \mathrm{C}, 250{ }^{\circ} \mathrm{C}$, and $230{ }^{\circ} \mathrm{C}$, respectively. The retention times for phe$d_{10}$, BPA, and NP were $9.082 \mathrm{~min}, 9.631 \mathrm{~min}$, and $11.024 \mathrm{~min}$, respectively. The quantitative and qualitative ions of the compounds for selected ion monitoring (SIM) mode operation were $m / z 357,358$, and 372 for BPA (2TMS derivative), $m / z 179,220$, and 292 for NP (1TMS derivative), and $m / z 187,188$, and 189 for phe- $d_{10}$. The method recoveries were in the range of $74.2-88.9 \%$, while the RSD values ranged from $0.6 \%$ to $2.9 \%$ to meet the detection requirements.

\subsubsection{In-situ observation of BPA and NP in algae samples}

To visualize the distribution of NP and BPA in U. pertusa, the algae samples were observed by a charge-coupled device (CCD) imaging system. After treated by two contaminants for $24 \mathrm{~h}$, the live $U$. pertusa were imaged immediately with a PlantView 100 system (Guangzhou Biolight Equipment Company, China). The excitation/emission wavelength for $\mathrm{NP}$ and BPA were set at $480 / 520 \mathrm{~nm}$ and $480 / 600 \mathrm{~nm}$, respectively. The exposure times were both fixed as $30 \mathrm{~s}$

\subsubsection{Determination of chlorophyll content}

Approximately $0.2 \mathrm{~g}$ of fresh algae was ground and extraction by 25 $\mathrm{mL} 95 \%$ ethanol in darkness at $4{ }^{\circ} \mathrm{C}$ for $24 \mathrm{~h}$. The corresponding absorbance of the extract was measured with $95 \%$ ethanol as control at $649 \mathrm{~nm}$ and $665 \mathrm{~nm}$. The content of total chlorophyll $(\mathrm{a}+\mathrm{b})$ was calculated by the previous method described by Gong et al. (2018).

\subsubsection{Analysis of water quality}

The $\mathrm{pH}$ was measured by a $\mathrm{pH}$ meter (F2-Standard, Mettler-Toledo, Switzerland). The oxygen concentration dissolved in water was monitored by a portable dissolved oxygen meter (JPB-607A, INESA Analytical Instrument Co., Ltd., China). Nutrients, including $\mathrm{NO}_{-3}-\mathrm{N}, \mathrm{NO}_{-2}-\mathrm{N}$, $\mathrm{NH}_{+}-4 \mathrm{~N}$, and $\mathrm{PO}_{3-4}-\mathrm{P}$, were analyzed by a continuous flow analyzer (AutoAnalyzer III, Seal, Germany).

\subsection{Statistical analysis}

All lab-scale experiments were conducted in triplicate. Origin 2019b and IBM SPSS 20.0 were applied to process the data. One-way ANOVA analyzed the differences of the BPA or NP removal efficiency by $U$. pertusa among various treatments with the statistical significance recognized as $p$ values $<0.05$. The first-order kinetics (Eq. (1)) was applied to describe the removal process of BPA and NP:

$\ln \mathrm{C}_{\mathrm{t}}=\ln \mathrm{C}_{0}-k \mathrm{t}$

where $\mathrm{C}_{0}\left(\mu \mathrm{g} \mathrm{L}^{-1}\right)$ and $\mathrm{C}_{\mathrm{t}}\left(\mu \mathrm{g} \mathrm{L}^{-1}\right)$ are the initial BPA or NP concentration and residential BPA or NP concentration at the th hour in the aqueous solution, respectively; $k\left(\mathrm{~h}^{-1}\right)$ is the first-order degradation rate constant which is obtained as the slope of the linear regression to the BPA or NP removal data points.

\section{Results and discussion}

\subsection{The removal of BPA and NP in the presence of different intertidal macroalgae}

The changes of BPA and NP concentrations in the medium under various intertidal macroalgae (U. pertusa, U. prolifera, S. horueri, G. flabelliformis, G. lemaneiformis, and C. fragile) treatment were observed with the initial concentration of target phenolic EDCs as 100 $\mu \mathrm{g} \mathrm{L}^{-1}$. Both BPA and NP were removed to some extent from the medium by different intertidal macroalgae (Fig. 1a-b). Above $80 \%$ of NP removal efficiency was obtained by all tested algal species within $8 \mathrm{~h}$ exposure. In contrast, the BPA exhibited marked removal efficiency differences among texted algal species during $36 \mathrm{~h}$ exposure, and the values decreased as the following order of $U$. pertusa $>U$. prolifera $>$ S. horueri $>$ G. lemaneiformis $>$ G. flabelliformis $>C$. fragile. Except the C. fragile, the order of the EDCs removal efficiency could be expressed as: green algae $>$ brown algae $>$ red algae. In most cases, the EDCs removal efficiency of the green algae was much higher than that of the brown and red algae. For U. pertusa, the percentage of BPA removal was approximately $100 \%$, while that for G. flabelliformis and C. fragile was less than one-third of the available BPA in the medium. Simultaneously, inapparent difference $(p>0.05)$ between non-algal control treatment and algal treatment with these two contaminants were observed based on the total chlorophyll contents (data not shown) during the whole experiment. These results suggested that various intertidal macroalgae possessed the different potential for phenolic EDCs removal. These differences in removal efficiency by various algal species might be ascirbed to specific morphological and physiological characteristics of the algal cells. The proteins and polysaccharides contain a variety of negatively charged oxygen and nitrogen functional groups to make algae cells exhibit negative charge (Zhang et al., 2019a). The hydrophobic organic compounds may interact electrostatically and adsorbed onto algae cells after that. The $\mathrm{pK} a$ values of BPA and NP were 9.6 and 10.25 , respectively. BPA and NP could act as electron donors when they interact with functional groups on living cells and be removed by electrostatic interaction. Additionally, differences in the ratio of surface to volume (S/V) may also contribute to the differences in BPA and NP removal. The higher $\mathrm{S} / \mathrm{V}$ of macroalgae suggests a high potential for sorption and subsequent interaction with organic contaminants (Qiu et al., 2017).

The average removal rates of both contaminants by various intertidal macroalgae were also calculated based on the residual concentration in solution at the exposure period. Fig. 1c-d displayed substantial differences in removal rates among species. The average removal rates for both contaminants were decreased along with exposure time while removal rates by $U$. pertusa were significantly higher than those of other algae during all exposure generally. The maximum average removal rate by $U$. pertusa could be achieved to $7.4 \mu \mathrm{g} \mathrm{h}{ }^{-1}$ for BPA and $25.3 \mu \mathrm{g} \mathrm{h}^{-1}$ for NP. Additionally, within each contaminant division studied, different pollutants also displayed different removal efficiency by the same algae. In general, the NP removal efficiency by all the six algal species was above 1.5 times than that of BPA. The logarithmic octanol/ water partition coefficients $\left(\log K_{\text {ow }}\right)$ for BPA and NP is 3.32 and 5.99, respectively (Liu et al., 2017; Wang et al., 2013), which means NP may be readily accumulated by algae owing to its relatively higher 

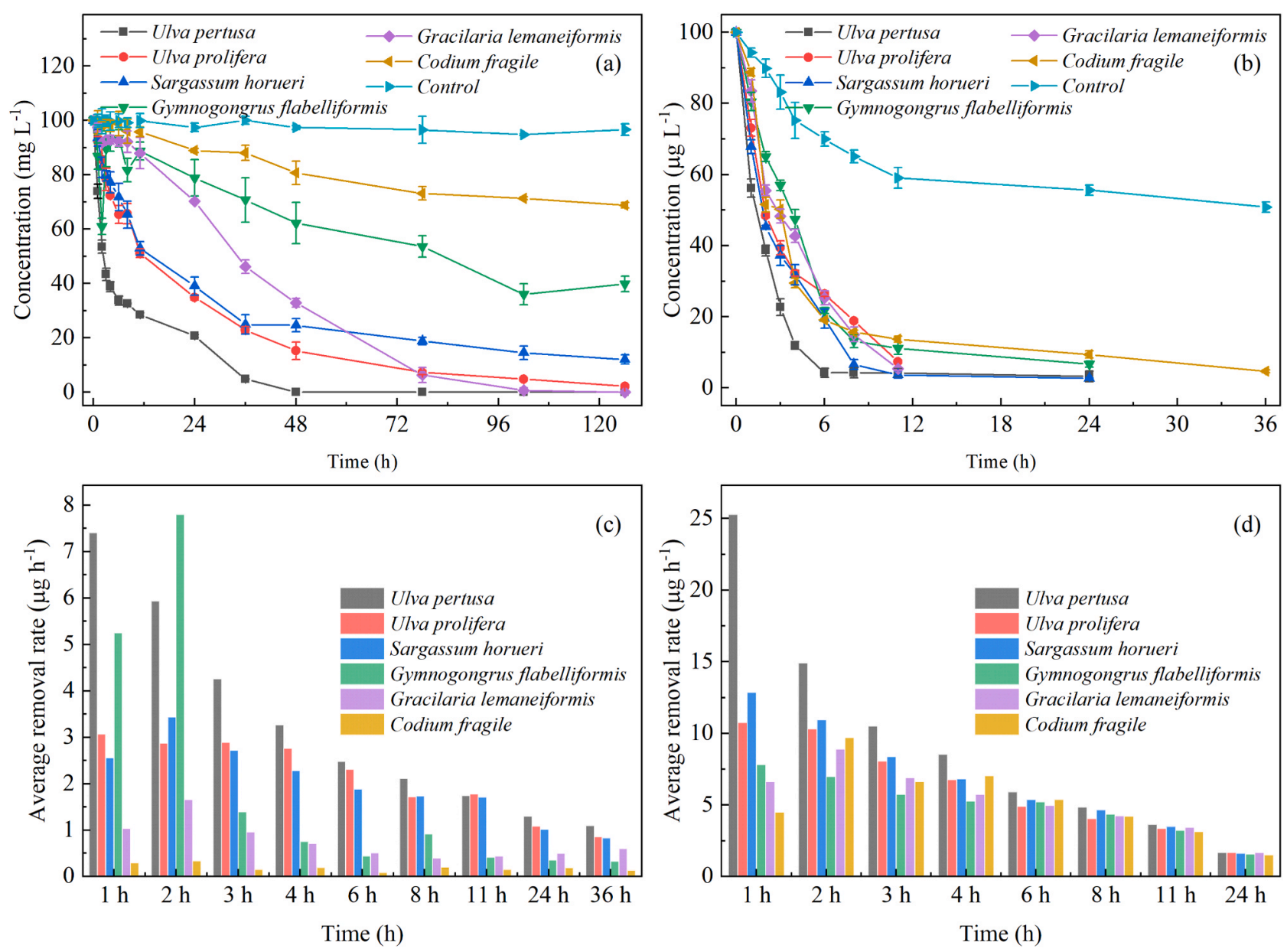

Fig. 1. The removal efficiency (a, b) and average removal rate (c, d) of bisphenol A (a, c) and nonylphenol (b, d) by different intertidal algal species.

hydrophobic property. The previous study (Zhang et al., 2019a) also found that adsorptive capacity of the polycyclic aromatic hydrocarbons with higher $\log K_{o w}$ value by algal detritus was higher than that of other polycyclic aromatic hydrocarbons with lower $\log K_{o w}$ values.

\subsection{The removal mechanisms and kinetics of BPA and NP in the presence of typical intertidal macroalgae}

The $U$. pertus a among the intertidal macro algae is widely distributed in the high tide zone to the low tide zone of China with abundant natural biomass (Sun et al., 2018). Therefore, the removal of the target phenolic EDCs using typical intertidal algae (U. pertusa) was further investigated by setting groups as non-algae with sterilization (CK1), algae treatment without sterilization (CK2), algae treatment with sterilization (T1), and heat-killed algae treatment with sterilization (T2). The changes of BPA and NP residual concentrations in the seawater medium were shown in Fig. $2 a-b$. The reduction of BPA in the treatment without algae (CK1) was below $5 \%$, indicating that the abiotic loss from processes such as photodegradation and volatilization was negligible. In contrast, the NP loss by abiotic factors was approximately $30 \%$ up to $6 \mathrm{~h}$ and increased slightly to $46 \%$ during the following incubation. More than $80 \%$ of BPA was achieved within $24 \mathrm{~h}$ and above $95 \%$ of NP was removed within $11 \mathrm{~h}$ with the presence of $U$. pertusa (T1) in comparison with the control group without algae addition (CK1), manifesting that algae were involved in the removal of BPA and NP. Additionally, the BPA concentrations in the medium with sterilization (T1) and non-sterilization (CK2) during 24-h incubation were reduced from $100.00 \mu \mathrm{g} \mathrm{L}^{-1}$ to19.69 and $13.39 \mu \mathrm{L} \mathrm{L}^{-1}$, respectively, while the NP concentrations were reduced from $100.00 \mu \mathrm{g} \mathrm{L}^{-1}$ to 4.26 , and $3.08 \mu \mathrm{g} \mathrm{L}^{-1}$, respectively.
There was no significant difference in the removal efficiency of NP between these two treatments ( $p>0.05$ ). However, the presence of bacteria promoted the removal efficiency of BPA by $8 \%$ during $24 \mathrm{~h}$ incubation, which suggested that it was the algae rather than bacteria was the main contributor for BPA and NP removal. The CCD imaging system which is a powerful real-time tool for observing organic pollutants within plant directly, was applied for the in-situ monitoring of the removal process of BPA and NP. The fluorescence signals of both BPA and NP were observed clearly in live $U$. pertusa (Fig. 3), which further confirmed the engagement of $U$. pertusa in BPA and NP removal.

The BPA concentration decreased from $100.00 \mu \mathrm{g} \mathrm{L}^{-1}$ to $67.25 \mu \mathrm{g} \mathrm{L}^{-1}$ within $6 \mathrm{~h}$, and then kept constantly in the treatments of heat-killed algae (T2). The NP showed the same tendency, with concentration decreasing dramatically from $100.00 \mu \mathrm{g} \mathrm{L}^{-1}$ to $10.83 \mu \mathrm{g} \mathrm{L}^{-1}$ within $11 \mathrm{~h}$, and then reaching equilibrium. The results indicated that the adsorption removal by $U$. pertusa played an essential role in the removal of BPA and NP, which was consistent with that of freshwater microalgae (Bai and Acharya, 2019; Wang et al., 2017). Similar rapid removal process of BPA and NP also occurred in the live algae treatment (T1). The BPA concentration in the treatment with live algae (T1) decreased from $100.00 \mu \mathrm{g} \mathrm{L}^{-1}$ to $33.73 \mu \mathrm{g} \mathrm{L}^{-1}$ within $6 \mathrm{~h}$ and plunged slowly to $4.8 \mu \mathrm{g} \mathrm{L}^{-1}$ with the following $30 \mathrm{~h}$. However, the residual concentrations of NP in the medium were comparable between the live algae and heat-killed algae addition treatment. The contents of BPA and NP in both live and heat-killed algae samples were also analyzed. The results showed that the amount of NP detected in the heat-killed algae (CK2) samples was $19.89 \mu \mathrm{g} \mathrm{g}^{-1}$, while that in the living algae (T1) treatment was only $12.92 \mu \mathrm{g} \mathrm{g}^{-1}$. This phenomenon further confirmed that the NP metabolic activity occurred due to the participant of live 

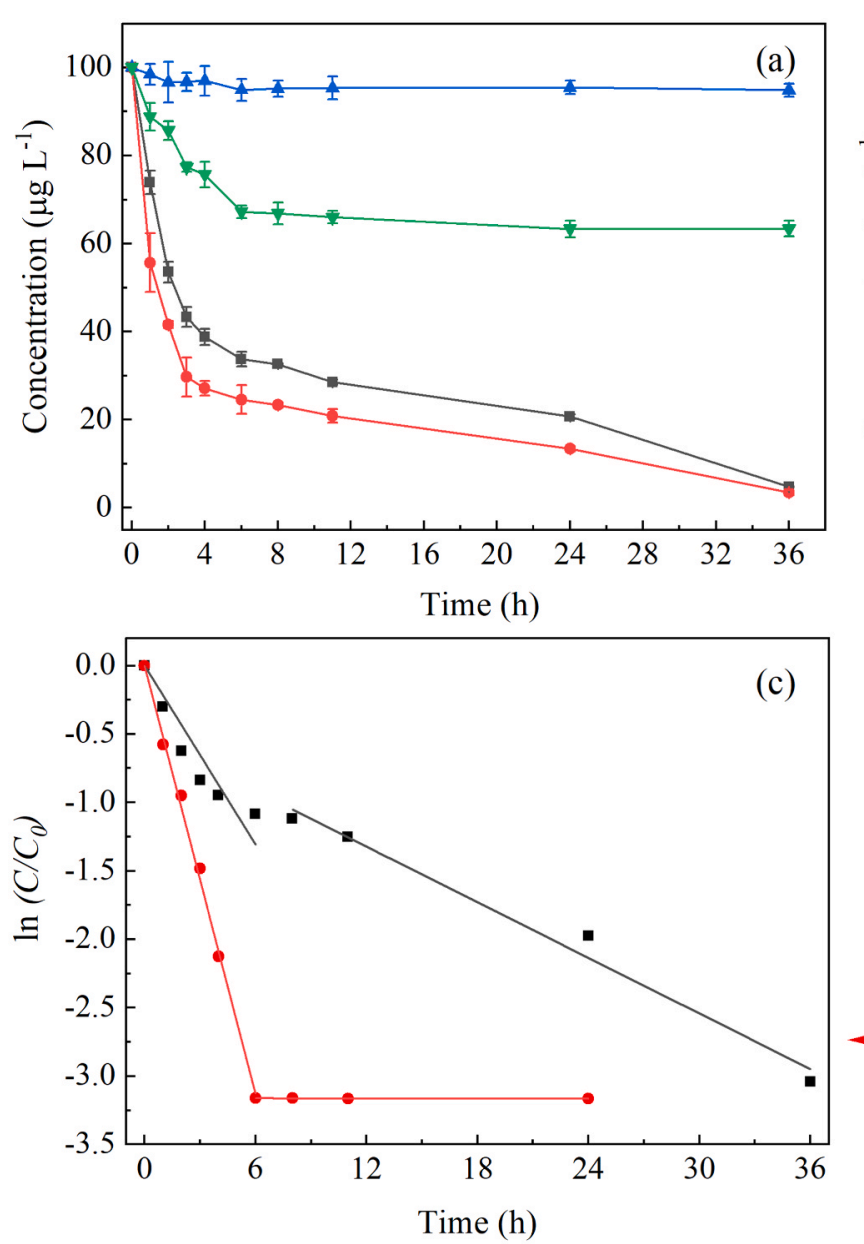

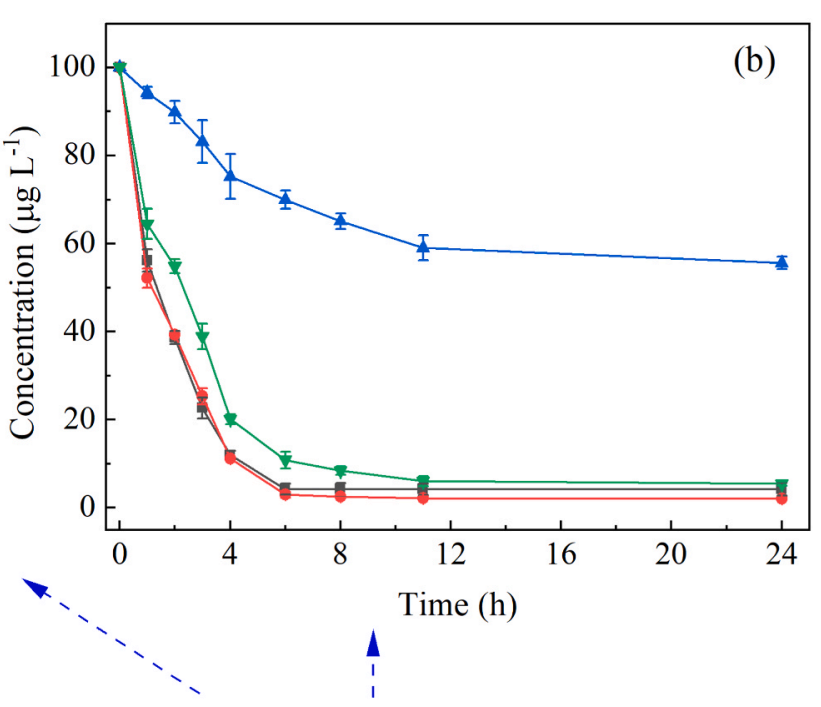

$\longrightarrow$ Algae treatment with sterilization
$\square$ Algae treatment without sterilization
$\square$ Without algae with sterilization
$\square-$ Heat-killed algae treatment with sterilization

\begin{tabular}{|ll|}
\hline - & BPA \\
NP \\
First-order kinetic fit of biosorption \\
\hline \\
\hline
\end{tabular}

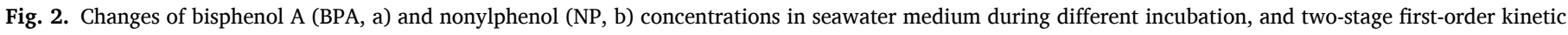
equations fitting curves of the adsorptive removal process and uptake removal process for BPA and NP (c).

macroalgal cells. NP biodegradation processes were widely reported in the incubation systems of bacteria (Mtibaà et al., 2020; Nowak et al., 2019; Różalska et al., 2015). Such processes could imply several pathways for the degradation of NP as ipso-hydroxylation or transformed to a metabolite with a nitro-group at the ortho-position of the phenol ring (Nowak et al., 2019). The metabolites derived from these processes could be carboxylic acids (Nowak et al., 2019), monohydroxyl NP (Mtibaà et al., 2020) or other non-identified lower molecular weight products. In algal system, Lopez-Pacheco et al. (2019) found that a consortium of Arthrospira maxima (blue-green microalga) and Chlorella vulgaris (green microalga) could succeed to remove and metabolite 4-NP to four metabolites involved the basic structure of 4-NP. However, less information has been shown in macroalgae system. The content of BPA in live algae (T1) and heat-killed algae (CK2) samples were $10.66 \mu \mathrm{g} \mathrm{g}^{-1}$ and $7.13 \mu \mathrm{g} \mathrm{g}^{-1}$, respectively, confirming the engagement of $U$. pertusa in the BPA removal. Only $44.8 \%$ of the BPA was detected in the treatment of live algae (T1) according to the mass balance study, which was much lower than its theoretical value (95.2\%). The probable reason may be that the BPA was metabolized by the related enzymes after being absorbed by the $U$. pertusa. Nakajima et al. (2007) asserted that several microalgae species could metabolize BPA to its glycosides and then release the metabolites into the media. Wang et al. (2017) reported that Desmodesmus sp.WR1 (freshwater green alga) could remove BPA from the culture medium and metabolize it to monohydroxybisphenol $\mathrm{A}$ glycoside, 2-hydroxy-3-hydroxymethybisphenol A, and its glycosides.

To better understand the removal kinetics of BPA and NP in the presence of intertidal macroalgae, a two-stage first-order kinetic equation was used to fit the adsorption degradation process (Process I) and the absorption degradation process (Process II) (Zhang et al., 2017). As it was shown in Fig. 2c, the rate constants of adsorption removal stage $\left(k_{\mathrm{a}}\right)$ for BPA and NP were $0.24 \mathrm{~h}^{-1}\left(\mathrm{R}^{2}=0.96\right)$ and $0.53 \mathrm{~h}^{-1}\left(\mathrm{R}^{2}=0.99\right)$, respectively, and that of the uptake removal stage $\left(k_{\mathrm{u}}\right)$ were $0.06 \mathrm{~h}^{-1}\left(\mathrm{R}^{2}\right.$ $=0.97)$ and $0.0001 \mathrm{~h}^{-1}\left(\mathrm{R}^{2}=0.99\right)$, respectively. The phenolic EDCs could undergo many natural attenuation processes such as photolysis, volatilization, adsorption, and biodegradation. However, the high removal efficiency of BPA and NP in the presence of the intertidal macroalgae suggested a potential new natural attenuation of the coastal waters contaminated with phenolic EDCs.

\subsection{The effects of environmental factors on BPA and NP removal by intertidal macroalgae}

Since the intertidal area is alternately exposed to the fluctuation of various environmental conditions, it is necessary to evaluate the influence of various factors on the removal of phenolic EDCs by intertidal macroalgae. Fig. 4a-b showed the effect of photoperiods on the removal of BPA and NP by $U$. pertusa. As it was shown in Fig. 4a, the removal efficiencies of BPA in full darkness treatment, photoperiod 12/12 (light/ darkness) treatment, and photoperiod 24/0 (light/darkness) treatment during the first $24 \mathrm{~h}$ were $31.1 \%, 77.3 \%, 79.31 \%$, respectively, which suggested the $U$. pertusa that received light could remove more BPA. Algae use light for autotrophic growth and photosynthetic activity (Singh and Singh, 2015). The complete darkness could inhibit the removal of BPA by the inhibition of $U$. pertusa metabolism. BPA removal started to increase in a $12 \mathrm{~h}$ photoperiod than under continuous light when entering the second light period (24-36 h). These phenomena 

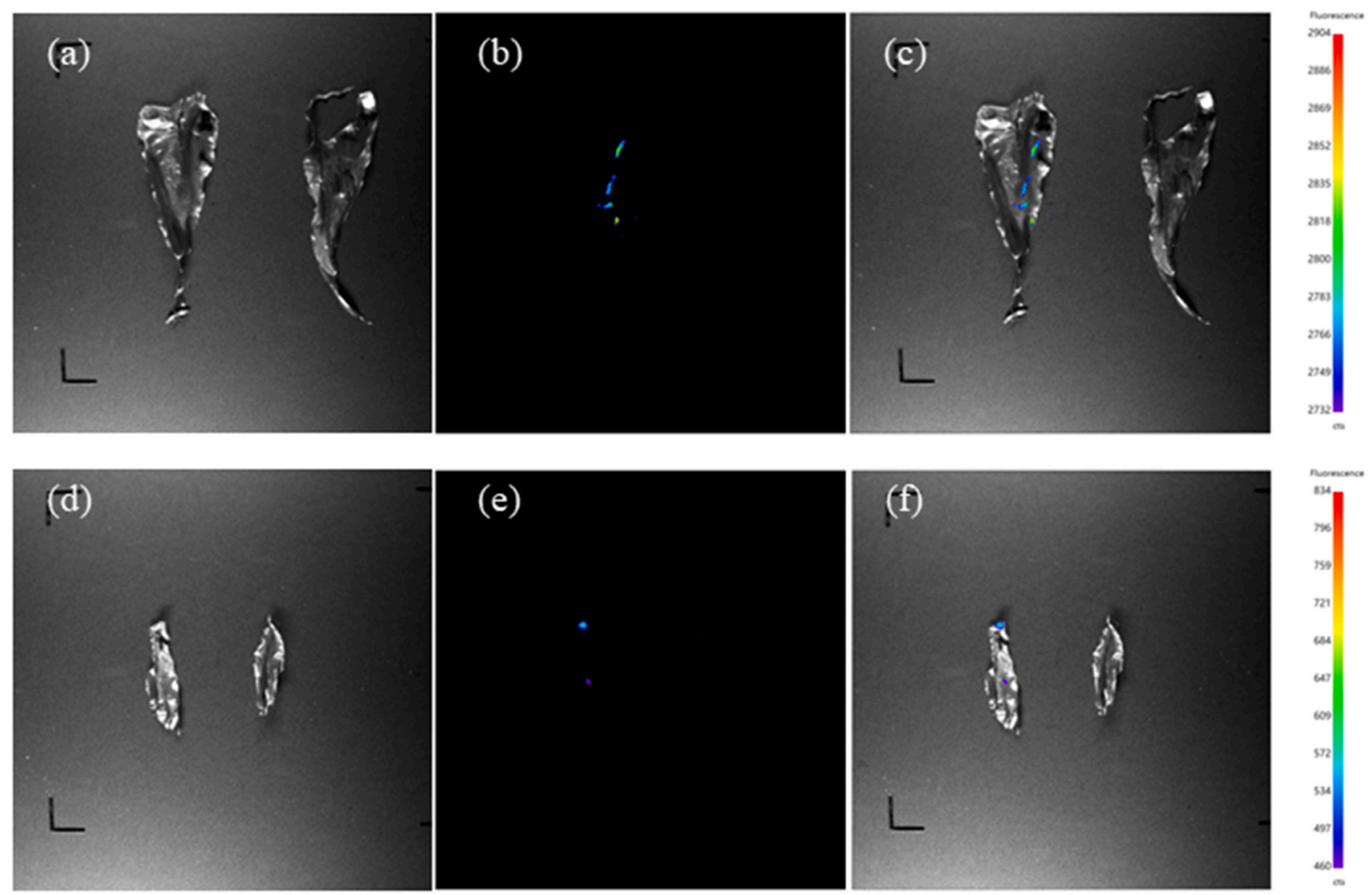

Fig. 3. Charge-coupled device (CCD) system image of the bisphenol A (a, b, c) and nonylphenol (d, e, f) distributed in control (right), and phenolic EDCs-algae (left) under bright field image (a, d), green fluorescence image (b, e) and overlay image (c, f). The color bar indicates the arbitrary interaction intensity corresponding to each pseudo color.

suggested that the removal efficiencies of BPA by $U$. pertusa was not disrupted in the dark but tended to increase when the algae were again exposed to the light right after the dark period. The NP removal efficiency showed no obvious enhancement among three photoperiod treatments during 24-h incubation. The removal efficiencies of NP in full darkness treatment, photoperiod 12/12 (light/darkness) treatment, and photoperiod 24/0 (light/darkness) treatment were $84.2 \%, 91.8 \%$ and $91.3 \%$, respectively. These results clearly indicated that the initial NP removal was mainly a passive physicochemical adsorption process. Biosorption is a passive process for algae to remove contaminants. The capability of freshwater algae to adsorb pollutants was highly dependent on its surface functional group, and the structure and the hydrophobicity of pollutants, rather than light irradiation (Hena et al., 2021). Although there was no significant difference in overall removal efficiency between two different photoperiod groups of BPA and NP, a natural diurnal light/dark regime (photoperiod $12 \mathrm{~h}$ light $/ 12 \mathrm{~h}$ darkness) may perform better in phenolic EDCs removal over a longer period.

The changes of BPA and NP removal efficiency by U. pertusa under various nutrient concentrations were displayed in Fig. 4c-d. For the BPA system, the BPA removal efficiency increased slightly with the increase of nutrient concentrations in the initial $11 \mathrm{~h}$. The removal efficiencies at low $\left(0 \mathrm{mg} \mathrm{L}^{-1}\left(\mathrm{NO}_{-3}-\mathrm{N}\right) / 0 \mathrm{mg} \mathrm{L}^{-1} \quad\left(\mathrm{PO}_{3-4}-\mathrm{P}\right)\right)$, middle $\left(1.0 \mathrm{mg} \mathrm{L}^{-1}\left(\mathrm{NO}_{-3}-\mathrm{N}\right) / 0.25 \mathrm{mg} \mathrm{L}^{-1}\left(\mathrm{PO}_{3-4} \mathrm{P}\right)\right)$, and high $\left(3.0 \mathrm{mg} \mathrm{L}^{-1}\right.$ (NO. $\left.\left.3^{-\mathrm{N}}\right) / 0.75 \mathrm{mg} \mathrm{L}^{-1}\left(\mathrm{PO}_{3-4}-\mathrm{P}\right)\right)$ nutrient levels were $71.4 \%, 73.3 \%$ and $74.7 \%$, respectively. In the following $24 \mathrm{~h}$, there was a similar trend of BPA removal under different nutrient conditions. It might be ascribed to the nutrients added into the three systems were exhausted. The kinetic fitting results showed that $k_{\mathrm{a}}$ values increased from 0.24 to $0.26 \mathrm{~h}^{-1}$ and the $k_{\mathrm{u}}$ values ranged from 0.06 to $0.07 \mathrm{~h}^{-1}$, indicating that there was no significant difference in the kinetic constants under the three nutrient treatment conditions. In the NP system, the removal rates of NP in the three nutrient systems were $95.7 \%, 96.6 \%$, and $98.4 \%$, respectively. The adsorption kinetic constant increased from $0.53 \mathrm{~h}^{-1}$ to $0.68 \mathrm{~h}^{-1}$, and the uptake kinetic constant was determined from $0.0001 \mathrm{~h}^{-1}$ increased to $0.32 \mathrm{~h}^{-1}$. Therefore, the eutrophication environment is slightly beneficial to the removal of phenolic EDCs by the U. pertusa.

Three salinity gradients were conducted to investigate the removal of the two contaminants by $U$. pertusa. As it was shown in Fig. 4e-f, the decrease in the salinity of the coastal water had a noticeable negative effect on the removal of BPA, but showed little influence on NP removal under different salinity conditions. The removal efficiencies of BPA at low $\left(16 \mathrm{~g} \mathrm{~L}^{-1}\right)$, middle $\left(24 \mathrm{~g} \mathrm{~L}^{-1}\right)$, and high $\left(32 \mathrm{~g} \mathrm{~L}^{-1}\right)$ salinity levels after 24 -h exposure were $79.3 \%, 87.1 \%$, and $92.2 \%$, respectively. According to the salting-out effect, the solubility of the organic compounds in the aqueous solution decreased when the ionic strength increased (Joseph et al., 2011). It may be the result of the salting-out effect which facilitate the transfer of contaminants from the liquid phase to the algal interface.

The effects of temperature on the removal of BPA and NP by $U$. pertusa were displayed in Fig. $5 \mathrm{a}-\mathrm{b}$. The $U$. pertusa possessed higher removal rate for $\mathrm{BPA}$ and $\mathrm{NP}$ at $10-20^{\circ} \mathrm{C}$ than that at $30^{\circ} \mathrm{C}$. The highest removal efficiency for BPA and NP during the whole incubation was $95.2 \%$ and $95.7 \%$, respectively, which was obtained at $20^{\circ} \mathrm{C}$. The rational reason might be that the optimum growth temperature of $U$. pertusa is $20-25^{\circ} \mathrm{C}$. The rates of photosynthesis-related enzymatic reactions and the photosynthetic rate increase with the rise of temperature within the tolerance temperature of $U$. pertusa (below $20^{\circ} \mathrm{C}$ ) (Kakinuma et al., 2006). The chemical composition (such as protein, lipids and carbohydrates) of the cells decreased when the temperature exceeded the tolerance temperature of algae (Singh and Singh, 2015), which could subsequently do harm to the function of chloroplasts and 

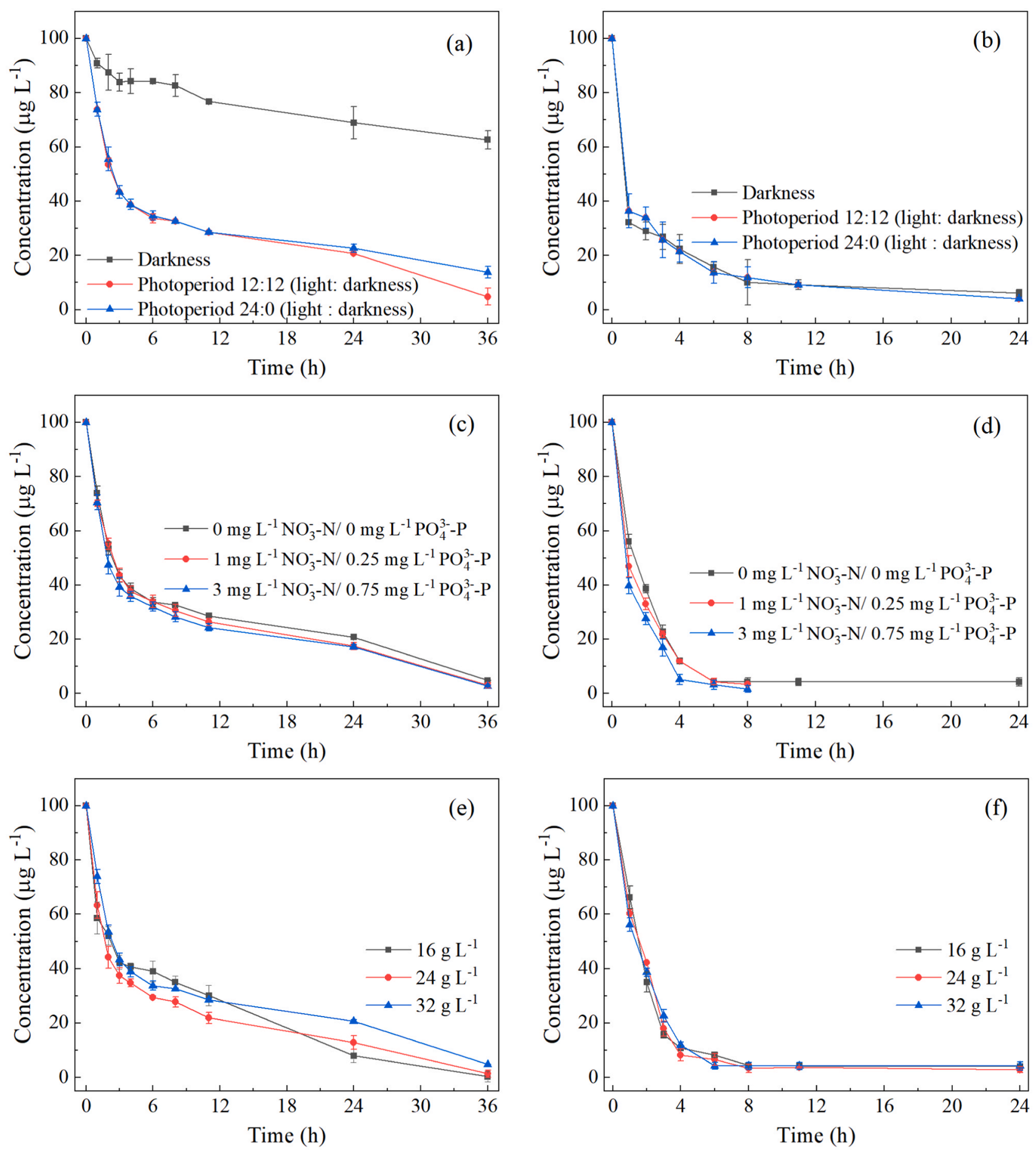

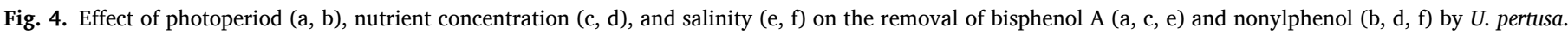

adverse to the uptake process of hydrophobic organic matter such as the phenolic EDCs in algae.

The removal of BPA and NP by $U$. pertusa was also evaluated under various initial concentrations. Both BPA and NP were removed efficiently as the time proceeded with the addition of $U$. pertusa. The removal efficiency of BPA by $U$. pertusa increased from $87.2 \%$ to $92.1 \%$ as initial BPA concentration increased from 50 to $1000 \mu \mathrm{g} \mathrm{L}^{-1}$ during 36-h exposure. Simultaneously, the removal efficiency by $U$. pertusa increased from $88.1 \%$ to $95.1 \%$ as the initial concentration of the NP increased from 50 to $1000 \mu \mathrm{g} \mathrm{L}{ }^{-1}$. Additionally, the functions of the average removal rate of BPA and NP with their initial concentration were also fitted. As it was shown in Fig. 5c, it displayed a linear relationship between the initial concentration and the average removal rate $\left(\mathrm{R}^{2}>0.99\right)$ for the two contaminants. The maximum average removal rate was $29.3 \mu \mathrm{g} \mathrm{h}^{-1}$ for BPA and $36.9 \mu \mathrm{g} \mathrm{h}^{-1}$ for NP. It is generally acknowledged that the removal rate increases linearly with substrate concentration at low ranges, but reaches a plateau at high ranges because of its toxicity to the organism. However, the linear relationship was maintained even at $1000 \mu \mathrm{g} \mathrm{L}^{-1}$, indicating that no toxic effects occurred at such high initial concentrations of the target contaminants. It was reported that microalgae exposed to phenolic EDCs at lower concentrations $\left(<10 \mathrm{mg} \mathrm{L}^{-1}\right)$ displayed no apparent growth inhibition 

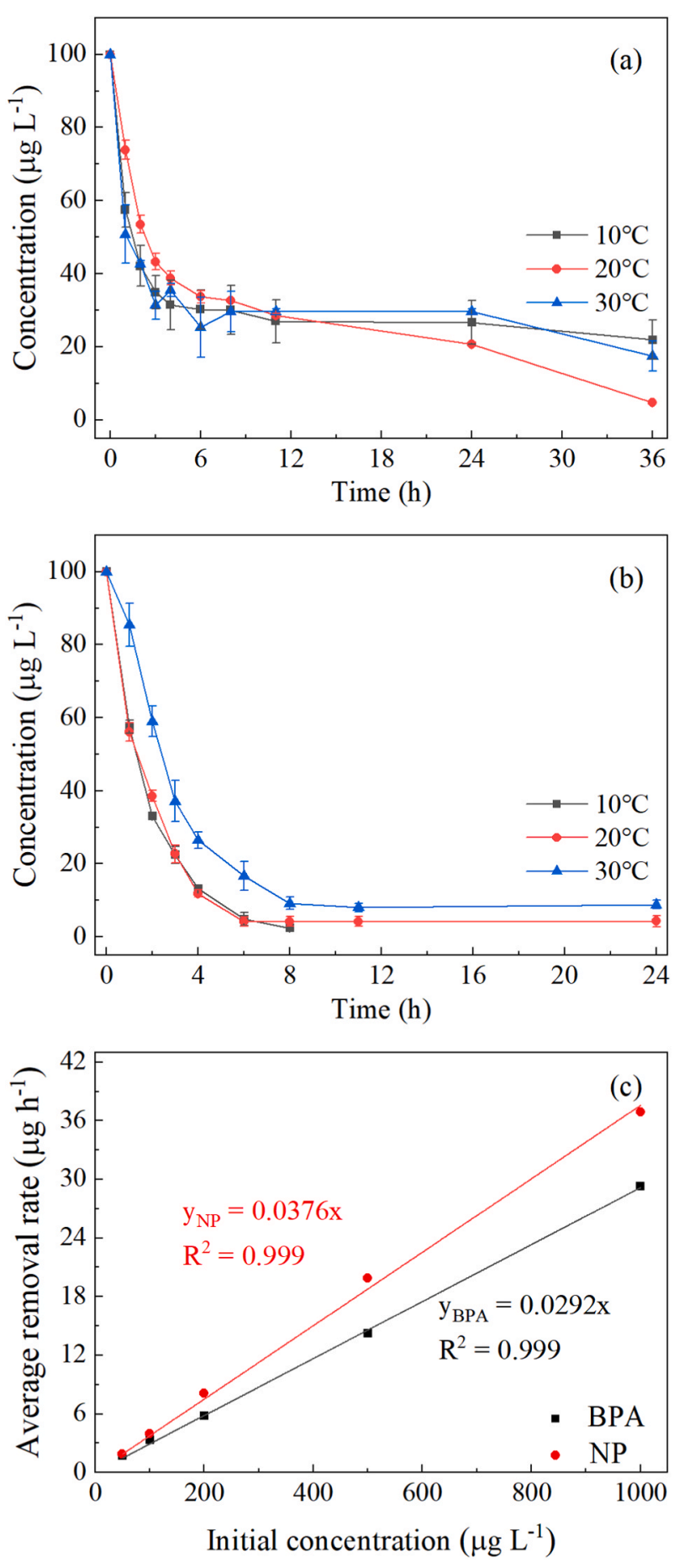

Fig. 5. Effect of temperature on the removal of bisphenol A (BPA, a) and nonylphenol (NP, b) by $U$. pertusa, and average removal rates as a function of the initial concentration of BPA and NP (c).

(Esperanza et al., 2020; Wang et al., 2017). However, the growth inhibition would be increased with the duration of exposure and at high concentrations of pollutants (Esperanza et al., 2020). Therefore, the good linear relationship between the average removal rate and the initial concentration could be ascribed to that their reaction time was less than $48 \mathrm{~h}$, or the low phenolic EDCs level $\left(1000 \mu \mathrm{g} \mathrm{L}^{-1}\right)$ was not toxic to $U$. pertusa. This result indicated that $U$. pertusa possessed outstanding adaptability and metabolic flexibility for phenolic EDCs.

\subsection{Pilot-scale investigation on the phenolic EDCs removal by intertidal macroalgae}

Pilot-scale experiments with seawater contaminated by BPA and NP were operated in continuous conduction mode for $180 \mathrm{~h}$. The results showed that the BPA and NP at the environmental relevant concentration $\left(100 \mu \mathrm{g} \mathrm{L}^{-1}\right)$ could be removed efficiently even after three cycles with the $U$. pertusa (Fig. 6a-b), suggesting that the intertidal macroalgae possessed great potential on the removal of phenolic EDCs from coastal waters. Interestingly, the BPA removal rate by $U$. pertusa was accelerated as the number of cycles increasing, while NP showed fluctuant trends. From Fig. $6 \mathrm{c}-\mathrm{d}$, the BPA adsorption removal rate constant $\left(k_{\mathrm{a}}\right)$ and uptake removal rate constant $\left(k_{\mathrm{u}}\right)$ calculated from the two-stage firstorder model for three cycles varied in a range of $0.047-0.103 \mathrm{~h}^{-1}$ and $0.044-0.087 \mathrm{~h}^{-1}$, respectively, while that for NP was $0.116-0.195 \mathrm{~h}^{-1}$ and $0.907-0.960 \mathrm{~h}^{-1}$, respectively. The observed $k_{\mathrm{a}}$ for both BPA and NP in the pilot-scale assays was just one-fifth of $k_{\mathrm{a}}$ that obtained from labscale experiments, while the $k_{\mathrm{u}}$ for NP at pilot-scale experiments was 600-1000-fold higher than that of lab-scale experiments. A rational explanation for the performance differences between lab-scale and pilotscale experiments might be the fluctuation of water quality parameters during continuous operation (Miklos et al., 2018). The pH, DO, NO. ${ }_{3}-\mathrm{N}$ concentration, NO- $2-\mathrm{N}$ concentration, $\mathrm{NH}_{+}{ }_{4}-\mathrm{N}$ concentration, and $\mathrm{PO}_{3-4}$-P concentration at lab scale were $8.29,6.8 \mathrm{mg} \mathrm{L}^{-1}, 0.385 \mathrm{mg} \mathrm{L}^{-1}$, $0.008 \mathrm{mg} \mathrm{L}^{-1}, \quad 0.111 \mathrm{mg} \mathrm{L}^{-1}$, and $\quad 0.021 \mathrm{mg} \mathrm{L}^{-1}$, respectively. Compared with the lab-scale experiment, the initial water quality parameters of the pilot-scale experiment were characterized by high level of nutrients, moderate $\mathrm{pH}$, and lower DO (Fig. 7). The changes of water quality parameters between treatment without algae and treatment with algae during the whole pilot-scale experiment were displayed in Fig. 7. Based on the general comparison, the $\mathrm{pH}$ in the wastewater was enhanced with the addition of algae, which likely corresponded to a decrease in dissolved $\mathrm{CO}_{2}$ caused by enhanced photosynthesis and biomass production due to amendment with limiting nutrients (Wang et al., 2017). The DO in the algae-addition system was higher than that in the control system due to the algal photosynthesis. NO. $3^{-\mathrm{N}}$ and $\mathrm{PO}_{3-4}$-P concentration decreased with the cycle numbers increase in the pilot-scale experiment in comparison with the treatment without algae, indicating the consumption of nutrients. Usage of seaweeds for the treatment of marine aquaculture wastes has been proposed by several authors since marine seaweeds have high capacities for absorption and metabolism of $\mathrm{N}$ and P-compounds excreted by marine animals (Amosu et al., 2016; Chaitanawisuti et al., 2011; Dobson et al., 2020). Regarding the removal efficiency achieved in the lab-scale experiment, it can be stated that higher nutrient concentration was beneficial to the removal of phenolic EDCs. Interestingly, the $\mathrm{NH}_{+}{ }_{4}^{-\mathrm{N}}$ level in both the algal and non-algal treatments increased in the following two cycles while $\mathrm{NH}_{+}$ ${ }_{4} \mathrm{~N}$ le concentration in the algae treatment was five-fold lower than that in the control algae, especially during the cycle 3 . However, the NO${ }_{2}-\mathrm{N}$ level in the wastewater showed a tendency inversely, i.e., increasing the cycle number causing a fluctuated increase in the $\mathrm{NO}_{2}-\mathrm{N}$ concentration from $0.12 \mathrm{mg} \mathrm{L}^{-1}$ to $0.46 \mathrm{mg} \mathrm{L}^{-1}$ in the cycle 2 , and decreased to $0.07 \mathrm{mg} \mathrm{L}^{-1}$ in the cycle 3 . The reason for the sharp enhancement of $\mathrm{NH}_{+} 4-\mathrm{N}$ content in cycle 3 under non-algae treatment was not clear yet. However, it was assumed to be the result of a complex of amination by bacteria that converted the organic nitrogen in mariculture wastewater to ammonium, which was then uptake by algae for growth and transformed to nitrite. These findings demonstrated that intertidal algae such as $U$. pertusa could be used as biofilters for eliminating phenolic EDCs and regulating seawater quality.

\subsection{Field investigation on the phenolic EDCs removal in the presence of intertidal macroalgae}

To obtain the further evidence on the phytoremediation of NP and BPA by intertidal macroalgae in coastal waters, the regional differences 
- Treatment without algae - Treatment with algae
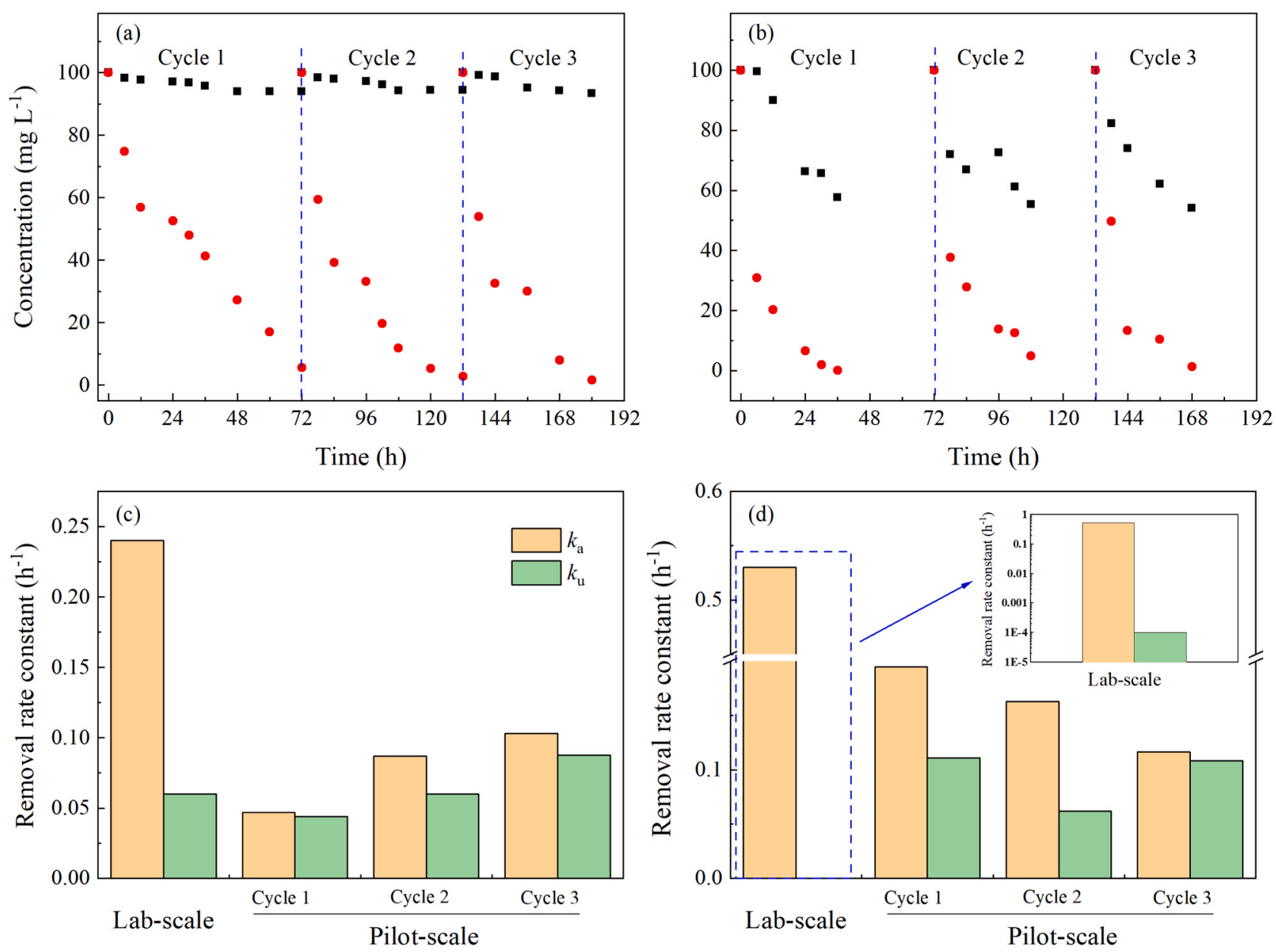

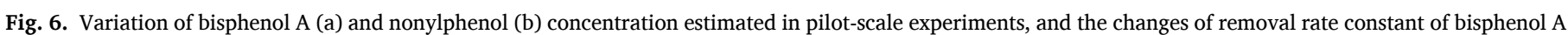

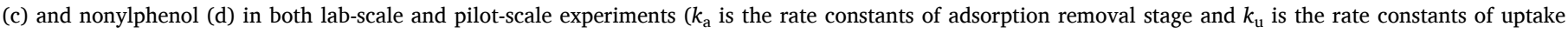
removal stage. Inset: the removal rate constant of nonylphenol in the lab-scale experiment.).

in the concentrations of NP and BPA in the coastal waters were evaluated between the intertidal zone with abundant $U$. pertusa and the adjacent zone without $U$. pertusa (control investigation). As it was displayed in Fig. 8, the concentrations of NP and BPA in the intertidal zone with abundant $U$. pertusa were detected as $26 \pm 2 \mathrm{ng} \mathrm{L}^{-1}$ and $353 \pm 12 \mathrm{ng} \mathrm{L}^{-1}$, much lower than that (48.64 $\pm 1.30 \mathrm{ng} \mathrm{L}^{-1}$ for NP and $632 \pm 13 \mathrm{ng} \mathrm{L}^{-1}$ for BPA) in the adjacent zone without $U$. pertusa. The results showed the essential engagement of intertidal algae in the natural attenuation of EDCs in coastal waters.

\section{Conclusions}

All the six intertidal macroalgae investigated in this study could remove BPA and NP at an environmental relevant concentration from seawater. Except the Codium fragile, the order of the EDCs removal efficiency could be expressed as: green algae $>$ brown algae $>$ red algae. The $U$. pertusa which is widely distributed along the coastline with abundant biomass was the most efficient one for the BPA and NP removal. The removal mechanisms included the initial rapid biosorption process, followed by a slow accumulation and biodegradation. Both BPA and NP removal efficiencies were species-specific and slightly dependent on surrounded temperature and nutrient concentrations. The removal of BPA was also enhanced by higher salinity and the presence of light, while that of NP from contaminated water was little affected by salinity and photoperiod. There was a linear relationship between the initial concentration and the average removal rate, even at relatively high initial concentrations $\left(1000 \mu \mathrm{g} \mathrm{L}^{-1}\right)$, indicating the high removal capacity of EDCs by the intertidal macroalgae. The BPA and NP at the environmental relevant concentration could be removed efficiently even after three cycles, demonstrating the high removal potential of EDCs using the intertidal macroalgae. Much lower concentrations of NP and BPA in the coastal waters of the intertidal zone with abundant $U$. pertusa were detected when compared with those in the adjacent zone without $U$. pertusa, confirming the phytoremediation of EDCs in the presence of intertidal macroalga. These findings demonstrated that intertidal macroalgae could play essential role in the natural attenuation of EDCs and enhance the removal of phenolic EDCs from coastal waters.

\section{CRediT authorship contribution statement}

Cui Zhang: Formal analysis, Investigation, Methodology, Data curation, Roles/Writing - original draft. Jian Lu: Conceptualization, Funding acquisition, Investigation, Methodology, Project administration, Supervision, Resources, Roles/Writing - original draft, Writing review \& editing. Jun Wu: Methodology, Investigation, Software, Writing - review \& editing.

\section{Declaration of Competing Interest}

The authors declare that they have no known competing financial 
- Treatment without algae - Treatment with algae

$\begin{array}{llllll}\text { Cycle } 1 & \text { Cycle 2 } & \text { Cycle } 3 & \text { Cycle } 1 & \text { Cycle 2 } & \text { Cycle } 3\end{array}$
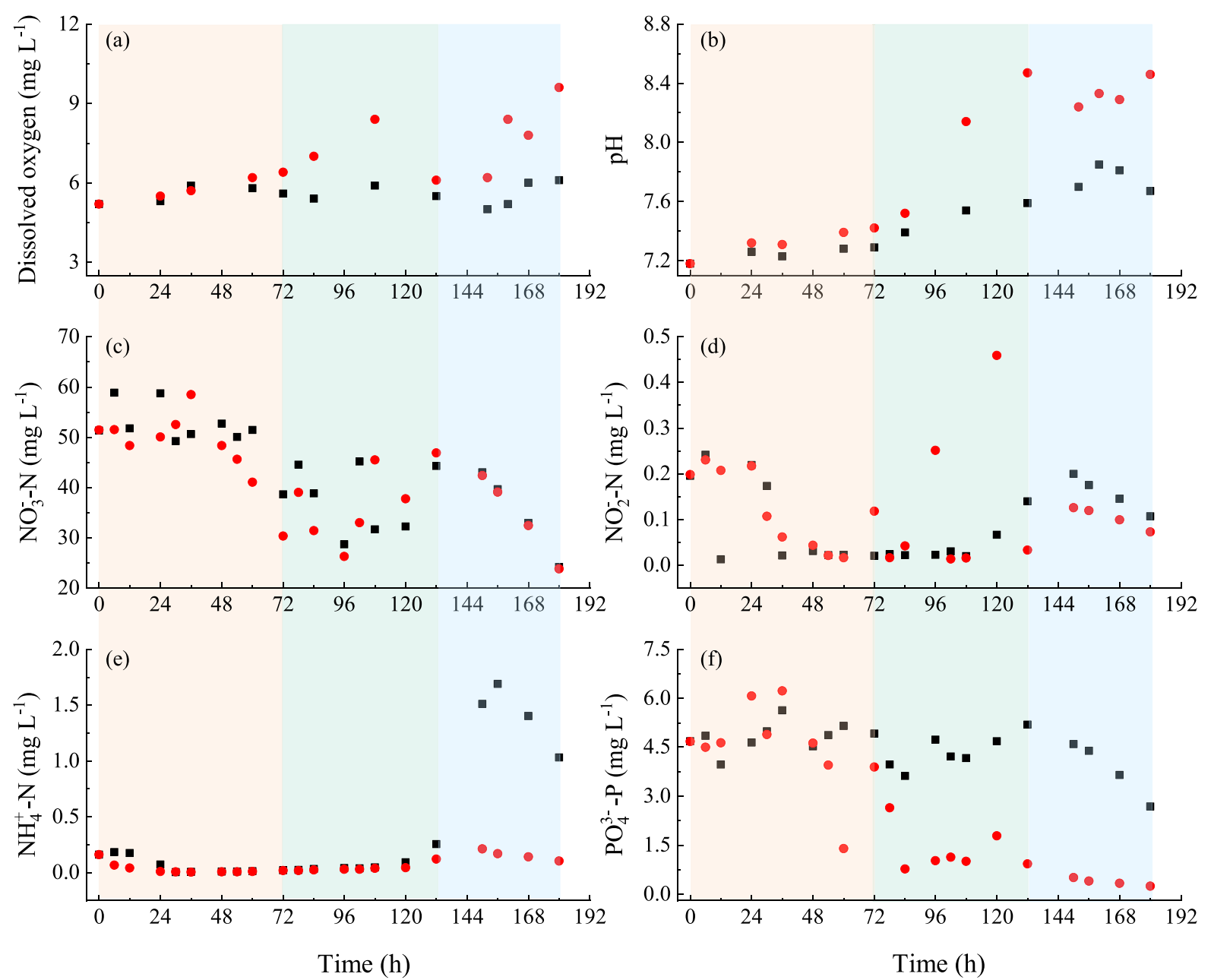

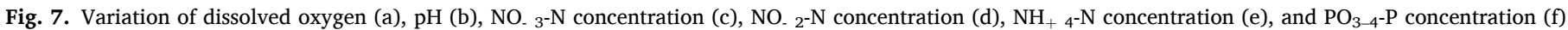
estimated in pilot-scale experiments.

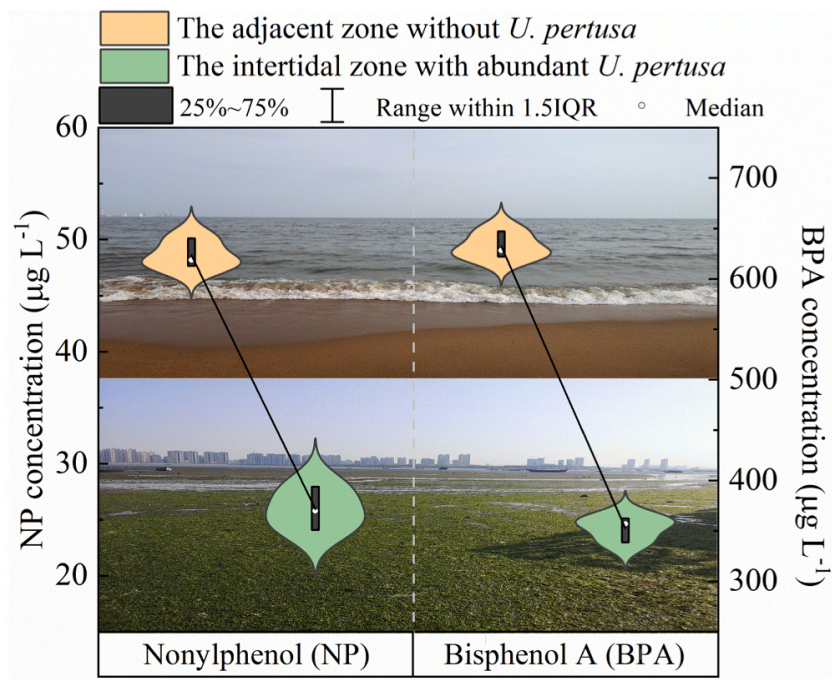

Fig. 8. Field investigation on concentrations of nonylphenol (NP) and bisphenol A (BPA) in the coastal waters with abundant $U$. pertusa and the adjacent zone without $U$. pertusa. interests or personal relationships that could have appeared to influence the work reported in this paper.

\section{Acknowledgments}

This work was financially supported by the National Natural Science Foundation of China (41671319), Taishan Scholars Program of Shandong Province (No. tsqn201812116), Science and Technology Service Network Initiative of the Chinese Academy of Sciences (KFJ-STS-QYZX114), One Hundred Talents Program of Chinese Academy of Sciences (Y629041021), Shandong Provincial Natural Science Foundation (ZR2020QD131), Two-Hundred Talents Plan of Yantai (Y739011021), Yantai Science and Technology Development Project (2020MSGY062).

\section{References}

Abargues, M.R., Giménez, J.B., Ferrer, J., Bouzas, A., Seco, A., 2018. Endocrine disrupter compounds removal in wastewater using microalgae: degradation kinetics assessment. Chem. Eng. J. 334, 313-321.

Amosu, A.O., Robertson-Andersson, D.V., Kean, E., Maneveldt, G.W., Cyster, L., 2016. Biofiltering and uptake of dissolved nutrients by Ulva armoricana (Chlorophyta) in a land-based aquaculture system. Int. J. Agric. Biol. 18, 298-304.

Bai, X.L., Acharya, K., 2019. Removal of seven endocrine disrupting chemicals (EDCs) from municipal wastewater effluents by a freshwater green alga. Environ. Pollut. 247, 534-540. 
Bazterrica, M.C., Alvarez, M.F., Iribarne, O., Botto, F., 2021. Macroalgae ecosystem engineering effects mediated by an invasive reef-builder polychaete in a Southwestern Atlantic coastal lagoon. J. Sea Res. 167, 101971.

Brito, L.O., Arantes, R., Magnotti, C., Derner, R., Pchara, F., Olivera, A., Vinatea, L., 2014. Water quality and growth of Pacific white shrimp Litopenaeus vannamei (Boone) in co-culture with green seaweed Ulva lactuca (Linaeus) in intensive system. Aquacult. Int. 22, 497-508.

Chaitanawisuti, N., Santhaweesuk, W., Kritsanapuntu, S., 2011. Performance of the seaweeds Gracilaria salicornia and Caulerpa lentillifera as biofilters in a hatchery scale recirculating aquaculture system for juvenile spotted babylons (Babylonia areolata). Aquacult. Int. 19, 1139-1150.

Cheng, Q., Jiang, Y., Jin, Z., Hui, C., Xu, L., Zhou, Q., Zhao, Y., Du, L., Jiang, H., 2020 Enhanced excretion of extracellular polymeric substances associated with nonylphenol tolerance in Dictyosphaerium sp. J. Hazard. Mater. 395, 122644.

Dobson, G.T., Duy, N.D.Q., Paul, N.A., Southgate, P.C., 2020. Assessing potential for integrating sea grape (Caulerpa lentillifera) culture with sandfish (Holothuria scabra) and Babylon snail (Babylonia areolata) co-culture. Aquaculture 522, 735153.

El Gamal, A.A., 2010. Biological importance of marine algae. Saudi Pharm. J. 18, 1-25.

Esperanza, M., Seoane, M., Servia, M.J., Cid, Á., 2020. Effects of Bisphenol A on the microalga Chlamydomonas reinhardtii and the clam Corbicula fluminea. Ecotoxicol. Environ. Saf. 197, 110609.

Fabre, E., Dias, M., Costa, M., Henriques, B., Vale, C., Lopes, C.B., Pinheiro-Torres, J., Silva, C.M., Pereira, E., 2020. Negligible effect of potentially toxic elements and rare earth elements on mercury removal from contaminated waters by green, brown and red living marine macroalgae. Sci. Total Environ. 724, 138133.

Gong, L., Zhang, S., Chen, D., Liu, K., Lu, J., 2018. Response of biofilms-leaves of two submerged macrophytes to high ammonium. Chemosphere 192, 152-160.

Hena, S., Gutierrez, L., Croué, J.-P., 2021. Removal of pharmaceutical and personal care products (PPCPs) from wastewater using microalgae: a review. J. Hazard. Mater. 403, 124041.

Joseph, L., Zaib, Q., Khan, I.A., Berge, N.D., Park, Y.-G., Saleh, N.B., Yoon, Y., 2011. Removal of bisphenol A and $17 \alpha$-ethinyl estradiol from landfill leachate using singlewalled carbon nanotubes. Water Res. 45, 4056-4068.

Kakinuma, M., Coury, D.A., Kuno, Y., Itoh, S., Kozawa, Y., Inagaki, E., Yoshiura, Y., Amano, H., 2006. Physiological and biochemical responses to thermal and salinity stresses in a sterile mutant of Ulva pertusa (Ulvales, Chlorophyta). Mar. Biol. 149, 97-106.

Liu, D., Wu, S., Xu, H., Zhang, Q., Zhang, S., Shi, L., Yao, C., Liu, Y., Cheng, J., 2017. Distribution and bioaccumulation of endocrine disrupting chemicals in water, sediment and fishes in a shallow Chinese freshwater lake: Implications for ecological and human health risks. Ecotoxicol. Environ. Saf. 140, 222-229.

Liu, J., Wang, Z., Lin, W., 2010. De-eutrophication of effluent wastewater from fish aquaculture by using marine green alga Ulva pertusa. Chin. J. Oceanol. Limn. 28, 201-208.

Lopez-Pacheco, I.Y., Salinas-Salazar, C., Silva-Nunez, A., Rodas-Zuluaga, L.I., DonosoQuezada, J., Ayala-Mar, S., Barcelo, D., Iqbal, H.M.N., Parra-Saldivar, R., 2019. Removal and biotransformation of 4-nonylphenol by Arthrospira maxima and Chlorella vulgaris consortium. Environ. Res. 179, 108848.

Lu, J., Wu, J., Stoffella, P.J., Wilson, P.C., 2015. Uptake and distribution of bisphenol A and nonylphenol in vegetable crops irrigated with reclaimed water. J. Hazard. Mater. 283, 865-870.

Lu, J., Zhang, Y., Wu, J., Wang, J., Zhang, C., Lin, Y., 2019. Occurrence and spatial distribution of antibiotic resistance genes in the Bohai Sea and Yellow Sea areas, China. Environ. Pollut. 2019 (252), 450-460.

Lu, J., Zhang, C., Wu, J., Zhang, Y., Lin, Y., 2020a. Seasonal distribution, risks, and sources of endocrine disrupting chemicals in coastal waters: will these emerging contaminants pose potential risks in marine environment at continental-scale? Chemosphere 247, 125907.

Lu, J., Wu, J., Zhang, C., Zhang, Y., 2020b. Possible effect of submarine groundwater discharge on the pollution of coastal water: occurrence, source, and risks of endocrine disrupting chemicals in coastal groundwater and adjacent seawater influenced by reclaimed water irrigation. Chemosphere 250, 126323.

Lu, J., Lin, Y., Wu, J., Zhang, C., 2021. Continental-scale spatial distribution, sources, and health risks of heavy metals in seafood: challenge for the water-food-energy nexus sustainability in coastal regions? Environ. Sci. Pollut. Res. https://doi.org/ 10.1007/s11356-020-11904-8.

Lu, J., Zhang, Y., Wu, J., Wang, J., Cai, Y., 2020c. Fate of antibiotic resistance genes in reclaimed water reuse system with integrated membrane process. J. Hazard. Mater. $382,121025$.

Miklos, D.B., Hartl, R., Michel, P., Linden, K.G., Drewes, J.E., Hubner, U., 2018. UV/ $\mathrm{H}_{2} \mathrm{O}_{2}$ process stability and pilot-scale validation for trace organic chemical removal from wastewater treatment plant effluents. Water Res. 136, 169-179.

Mtibaà, R., Ezzanad, A., Aranda, E., Pozo, C., Ghariani, B., Moraga, J., Nasri, M., Manuel Cantoral, J., Garrido, C., Mechichi, T., 2020. Biodegradation and toxicity reduction of nonylphenol, 4-tert-octylphenol and 2,4-dichlorophenol by the ascomycetous fungus Thielavia sp HJ22: identification of fungal metabolites and proposal of a putative pathway. Sci. Total Environ. 708, 135129.

Naiel, M.A.E., Alagawany, M., Patra, A.K., El-Kholy, A.I., Amer, M.S., Abd El-Hack, M.E., 2020. Beneficial impacts and health benefits of macroalgae phenolic molecules on fish production. Aquaculture, 736186.

Nakajima, N., Teramoto, T., Kasai, F., Sano, T., Tamaoki, M., Aono, M., Kubo, A., Kamada, H., Azumi, Y., Saji, H., 2007. Glycosylation of bisphenol A by freshwater microalgae. Chemosphere 69, 934-941.

Nowak, M., Soboń, A., Litwin, A., Różalska, S., 2019. 4-n-nonylphenol degradation by the genus Metarhizium with cytochrome P450 involvement. Chemosphere 220, 324-334.

Qiu, Y., Zeng, E.Y., Qiu, H., Yu, K., Cai, S., 2017. Bioconcentration of polybrominated diphenyl ethers and organochlorine pesticides in algae is an important contaminant route to higher trophic levels. Sci. Total Environ. 579, 1885-1893.

Różalska, S., Soboń, A., Pawłowska, J., Wrzosek, M., Długoński, J., 2015. Biodegradation of nonylphenol by a novel entomopathogenic Metarhizium robertsii strain. Bioresour. Technol. 191, 166-172.

Singh, S.P., Singh, P., 2015. Effect of temperature and light on the growth of algae species: a review. Renew. Sust. Energ. Rev. 50, 431-444.

Sun, Y.Y., Zhou, W.J., Wang, H., Guo, G.L., Su, Z.X., Pu, Y.F., 2018. Antialgal compounds with antialgal activity against the common red tide microalgae from a green algae Ulva pertusa. Ecotoxicol. Environ. Saf. 157, 61-66.

Wang, B., Huang, B., Jin, W., Zhao, S., Li, F., Hu, P., Pan, X., 2013. Occurrence, distribution, and sources of six phenolic endocrine disrupting chemicals in the 22 river estuaries around Dianchi Lake in China. Environ. Sci. Pollut. Res. 20, 3185-3194.

Wang, R., Diao, P., Chen, Q., Wu, H., Xu, N., Duan, S., 2017. Identification of novel pathways for biodegradation of bisphenol A by the green alga Desmodesmus $\mathrm{sp}$. WR1, combined with mechanistic analysis at the transcriptome level. Chem. Eng. J. $321,424-431$.

Zhang, C., Lu, J., Wu, J., Luo, Y., 2017. Removal of phenanthrene from coastal waters by green tide algae Ulva prolifera. Sci. Total Environ. 609, 1322-1328.

Zhang, C., Lu, J., Wu, J., 2019a. Adsorptive removal of polycyclic aromatic hydrocarbons by detritus of green tide algae deposited in coastal sediment. Sci. Total Environ. 670, 320-327.

Zhang, C., Lu, J., Wu, J., Luo, Y., 2019b. Phycoremediation of coastal waters contaminated with bisphenol A by green tidal algae Ulva prolifera. Sci. Total Environ. 661, 55-62. 